\title{
Characterization and genetic diversity analysis of cotton cultivars using microsatellites
}

\author{
Cândida H.C. de Magalhães Bertini ${ }^{1}$, Ivan Schuster ${ }^{5}$, Tocio Sediyama ${ }^{4}$, Everaldo Gonçalves de Barros ${ }^{1,2}$ \\ and Maurílio Alves Moreira ${ }^{1,3}$ \\ ${ }^{1}$ Universidade Federal de Viçosa Instituto de Biotecnologia Aplicada à Agropecuária, Viçosa, MG, Brazil. \\ ${ }^{2}$ Universidade Federal de Viçosa, Departamento de Biologia Geral, Viçosa, MG, Brazil. \\ ${ }^{3}$ Universidade Federal de Viçosa, Departamento de Bioquímica e Biologia Molecular Viçosa, MG, Brazil. \\ ${ }^{4}$ Universidade Federal de Viçosa, Departamento de Fitotecnia, Viçosa, MG, Brazil. \\ ${ }^{5}$ COODETEC - Cooperativa Central de Pesquisa Agrícola, Cascavel, PR, Brazil .
}

\begin{abstract}
Genetic diversity and the relationship between varieties are of great importance for cotton breeding. Our work was designed to estimate the informativeness of the cotton (Gossypium hirsutum L.) simple sequence repeat (SSR) microsatellite locus and to estimate the genetic distance between 53 cotton cultivars as well as to select a set of SSR primers able to differentiate between the 53 cotton cultivars studied. After extracting DNA from the 53 cultivars and characterized it using 31 pairs of SSR primers we obtained a total of 66 alleles with an average of 2.13 alleles per SSR locus and values of polymorphism information content (PIC) varying from 0.18 to 0.62 , the dissimilarity coefficient varying from zero to 0.41 . Statistical analysis using the unweighted pair-group method using arithmetic average (UPGMA) revealed seven subgroups which were consistent with the genealogical information available for some of the cultivars. The SSR genetic profile obtained for each of the cultivars made it possible to discriminate 52 of the 53 cultivars. This study of the genetic diversity of cotton cultivars with SSR markers support the need to introduce new alleles into the gene pool of the breeding cultivars.
\end{abstract}

Key words: fingerprinting, Gossypium hirsutum L., genealogy, molecular markers.

Received: December 14, 2004; Accepted: August 25, 2005.

\section{Introduction}

Many cotton (Gossypium hirsutum L.) varieties have been developed from crosses between closely related ancestors but so far only limited increases in productivity have been obtained. Pressure for higher productivity in cotton farming has stimulated the search for more exotic germplasm, but although breeding methods have increased the efficiency of transferring alleles from exotic germplasm sources to cotton breeding gene pools many germplasm sources still remain underused. Van Esbroeck and Bowman (1998) have pointed out that genetic diversity ensures protection procedures against diseases and pests and thus provides a basis for future genetic gains.

Molecular markers have been widely used in genetic analyses, breeding studies and investigations of genetic diversity and the relationship between cultivated species and their wild parents because they have several advantages as

Send correspondence to Cândida H.C. de Magalhães Bertini. Rua Vicente Padilha 496, Bairro Vila União, 60.410-680 Fortaleza, CE, Brazil. E-mail: ch.bertini@uol.com.br. compared with morphological markers, including high polymorphism and independence from effects related to environmental conditions and the physiological stage of the plant.

For research involving cotton (Gossypium hirsutum L.) the most widely used molecular method has been the random amplified polymorphic DNA (RAPD) technique (Multani and Lyon, 1995; Tatineni et al., 1996; Iqbal et al., 1997; Lu and Myers, 2002), although allozymes (Wendel et al., 1992), restriction fragment length polymorphism (RFLP) (Wendel and Brubaker, 1993) and amplified fragment length polymorphism (AFLP) (Pillay and Myers, 1999; Abdalla et al., 2001) have all been used successfully in genetic diversity analyses in many species including cotton. In spite of the success of these methods the level of polymorphism detectable is low, with allozymes and RFLP markers having particularly low intra- and interspecific polymorphism, and these types of markers tend not efficient when applied to the genotyping of large germplasm collections (Liu et al., 2000a). 
Simple sequence repeat (SSR) markers (microsatellites) have been successfully employed in many genetic diversity studies (Liu et al., 2000b; Gutiérrez et al., 2002) and are useful for a variety of applications in plant genetics and breeding because of their reproducibility, multiallelic nature, codominant inheritance, relative abundance and good genome coverage (Powel et al., 1996). The availability and abundance of microsatellite markers throughout the cotton genome coupled with the fact that they are polymorphic, codominant and are based on the polymerase chain reaction (PCR) make them particularly useful in genetic diversity studies of cotton (Reddy et al., 2001), with in excess of 1000 microsatellite primers having already been isolated from cotton DNA genome libraries (Nguyen et al., 2004).

Molecular studies of the genetic diversity of cultivated cotton have generally shown low genetic diversity (Brubaker and Wendel, 1994; Tatineni et al., 1996; Iqbal et al., 1997). However, more work needs to be carried out and the purpose of the work described in our present paper was to investigate the genetic diversity of cotton plants cultivated in several regions of Brazil, Argentine and Paraguay with the specific objectives of estimating the informativeness of cotton microsatellite loci and selecting a set of microsatellite primers able to differentiate between the 53 cultivars studied and to estimate the genetic distance among 53 cotton cultivars cultivated on Cone Sur.

\section{Materials and Methods}

\section{Plant material and DNA extraction}

We investigated 53 Gossypium hirsutum L. cotton cultivars developed and released by public and private institutions in Brazil, Argentine and Paraguay (Table 1). For each cultivar we extracted total DNA from ten seeds using a method based on that described by McDonald et al. (1994).

Table 1 - Cotton cultivars analyzed in this study with their descriptive data. Except for cultivars 19, 20, 21 and 43 all cultivars were from Brazil.

\begin{tabular}{|c|c|c|c|c|c|}
\hline $\mathrm{N}$. & Origin $^{1}$ & Cultivar & Genealogy $^{2}$ & $\begin{array}{l}\text { Cropping-cycle } \\
\text { (days) }\end{array}$ & $\begin{array}{l}\text { Region, state or country where } \\
\text { planted }^{3}\end{array}$ \\
\hline 1 & CSIRO-Australia & Sicala 3-2 & $\begin{array}{l}\text { Acala1517-70/TamcotSP-37//DP6 } \\
\text { 1/csiro }\end{array}$ & $135-175$ & - \\
\hline 2 & EMBRAPA & CNPA ITA 90 & Selection in Deltapine AC-90 & $170 / 180$ & Cerrado \\
\hline 3 & Fundação MT & BRS 96 & Selection in EPAMIG 3 & $170 / 180$ & Cerrado \\
\hline 4 & EMBRAPA & BRS Facual & Sicala 34/cnpa sri5 & $170-180$ & Cerrado \\
\hline 5 & Fundação MT/EMBRAPA & BRS Antares & Selection in cnpa sri5 & $160-170$ & Cerrado \\
\hline 6 & Fundação MT & FMT Saturno & Selection in CS 50 & $160 / 170$ & Cerrado \\
\hline 7 & DELTA PINE & Delta-Opal & - & 145 & Most Brazilian regions \\
\hline 8 & BAYER SEEDS & Fiber Max 966 & Selection in cultivar Sicala 34 & 156 & Northeast of SP, GO, MS, MT, TO \\
\hline 9 & BAYER SEEDS & Fiber Max 986 & Selection in cultivar Sicala 3-2 & 160 & Northeast of SP, GO, MS, MT, TO \\
\hline 10 & IAC & IAC 17 & Selection in $\mathrm{IAC} \mathrm{RM}_{3}$ & 140 & SP \\
\hline 11 & IAC & IAC 19 & Yucatanense/N1-HOA//IAC RM RM $_{3}$ & 150 & SP \\
\hline 12 & IAC & IAC 20 & Selection in IAC 17 & 140 & SP \\
\hline 13 & IAC & IAC 21 & Selection in IAC 19 & 150 & SP \\
\hline 14 & IAC & IAC 22 & IAC 20/GH 11-9-75 & 140 & SP, central-western Brazil \\
\hline 15 & IAC & IAC 23 & Selection in IAC $20-R R$. & 150 & SP \\
\hline 16 & IAPAR & IPR 94 & IAPAR 71/Deltapine Acala 90 & $138-175$ & PR \\
\hline 17 & IAPAR & IPR 95 & CNPA ITA 90/IAPAR 71 & $138-175$ & $\mathrm{PR}$ \\
\hline 18 & IAPAR & IPR 96 & CNPA ITA 90/IAPAR 71 & $135-175$ & PR \\
\hline 19 & Argentine & Guazuncho 2 & Guazuncho/SP 8535 & - & Argentine and Paraguay \\
\hline 20 & Argentine & Cacique & MATACO/GUAZUNCHO & - & Argentine \\
\hline 21 & Argentine & Oro Blanco & SP2473/SIOKRA & - & Argentine \\
\hline 22 & SYNGENTA & Makina & KNX111/Acala SJ-5 & 160 & MT, MS, GO, SP, BA \\
\hline 23 & SYNGENTA & Fabrika & KNH390/Monar 135-366 & 175 & MT, MS, GO, SP, BA \\
\hline 24 & EMBRAPA & CNPA $7 \mathrm{H}$ & TAMCOT SP 37/IAC 17 & $120 / 130$ & $\begin{array}{l}\text { Northeastern and central-southern } \\
\text { Brazil }\end{array}$ \\
\hline 25 & EMBRAPA & CNPA $8 \mathrm{H}$ & - & $130 / 140$ & North and northeastern Brazil \\
\hline 26 & EMBRAPA & CNPAPrecoce1 & Selection in GH-11-9-75 & $110 / 120$ & $\begin{array}{l}\text { North and northeastern Brazil and the } \\
\text { Cerrado }\end{array}$ \\
\hline
\end{tabular}


Table 1 (cont.)

\begin{tabular}{|c|c|c|c|c|c|}
\hline $\mathrm{N}$. & Origin $^{1}$ & Cultivar & Genealogy $^{2}$ & $\begin{array}{l}\text { Cropping-cycle } \\
\text { (days) }\end{array}$ & $\begin{array}{l}\text { Region, state or country where } \\
\text { planted }^{3}\end{array}$ \\
\hline 27 & EMBRAPA & CNPAPrecoce2 & C-100-7-81/PNH3 & $110 / 120$ & $\begin{array}{l}\text { North and northeastern Brazil and the } \\
\text { Cerrado }\end{array}$ \\
\hline 28 & EMBRAPA & CNPAPrecoce 3 & C-80-18-80 / PNH3 & $170 / 180$ & Cerrado \\
\hline 29 & EMBRAPA & CNPA ITA 92 & Selection in Island 542 & $110 / 120$ & $\begin{array}{l}\text { North, northeastern and cen- } \\
\text { tral-western Brazil }\end{array}$ \\
\hline 30 & EMBRAPA & BRS 197 & Selection in cnpa sri5 & $170 / 180$ & Cerrado \\
\hline 31 & EMBRAPA & BRS Itaúba & Selection in CS 50 & $170 / 180$ & Cerrado \\
\hline 32 & EMBRAPA & BRS Aroeira & Selection in CNPA SRI5 & $160 / 170$ & Cerrado \\
\hline 33 & EMBRAPA & BRS Ipê & Selection in CNPA ITA 90 & $170 / 180$ & Cerrado \\
\hline 34 & EMBRAPA & BRSSucupira & Sicala $34 /$ cnpa srI5 & $160 / 180$ & Cerrado \\
\hline 35 & EMBRAPA & BRS 96-148 & Selection in CS 50 & 160 & Cerrado \\
\hline 36 & EMBRAPA & BRS 96-227 & Selection in CS 50 & 157 & Cerrado \\
\hline 37 & Fundação MT & FMT Fetagri & Selection in CNPA SRI5 & 146 & MT \\
\hline 38 & EPAMIG & Alva & Double Haploid (C-25-1-80) & 120 & MG \\
\hline 39 & EPAMIG & Redenção & Selection in IAC 17 & $120-150$ & MG \\
\hline 40 & EPAMIG & Epamig 5 & Selection in C $-25-1-80$ & $120-140$ & MG and central-western Brazil \\
\hline 41 & EPAMIG & Liça & Double Haploid (C -24-5-78) & $120-140$ & MG and central-western Brazil \\
\hline 42 & EPAMIG & MG/UFU 91-02 & S 6046/IAC 17 & $120-140$ & MG \\
\hline 43 & Paraguay & IAN 338 & CHACO 510/ISA 205//Reba P279 & $140-160$ & Paraguay \\
\hline 44 & COODETEC & CD 401 & SP86/ISA205 & $130-140$ & MS, PR and SP \\
\hline 45 & COODETEC & CD 402 & DP Ac 90//IAC 20/S295*IAC 20 & 140 a 155 & $\mathrm{BA}, \mathrm{GO}, \mathrm{MT}, \mathrm{MS}, \mathrm{MG}, \mathrm{SP}$ \\
\hline 46 & COODETEC & CD 403 & DP Ac 90//IAC 20/S295*IAC 20 & $140-145$ & BA, GO, MT, MS, MG, SP \\
\hline 47 & COODETEC & CD 404 & CHACO 520/DP Ac90 & 140 a 160 & MS, MT e PR. \\
\hline 48 & COODETEC & CD 405 & CNPA86-387/P288//PR 3060/87 & 145 a 155 & $\mathrm{PR}$ and $\mathrm{SP}$. \\
\hline 49 & COODETEC & CD 98-87 & OC92-165/Sicala 3-3 & - & - \\
\hline 50 & COODETEC & CD 98-101 & OC92-165/Sicala 3-3 & - & - \\
\hline 51 & COODETEC & CD 406 & OC92-165/Sicala V1 & 140 a 160 & $\begin{array}{l}\mathrm{BA}, \mathrm{GO}, \mathrm{SP}, \mathrm{MG}, \mathrm{MT}, \mathrm{MS} \text { and } \\
\text { Northern Brazil . }\end{array}$ \\
\hline 52 & COODETEC & CD 407 & DP Ac90//IAC 20/S295 & 140 a 160 & $\begin{array}{l}\text { BA, GO, MG, SP, MT, PR, MS and } \\
\text { Northern Brazil. }\end{array}$ \\
\hline 53 & COODETEC & CD 98-440 & DP Ac 90//IAC 20/S295*IAC 20 & - & - \\
\hline
\end{tabular}

${ }^{1}$ Key: (research institutes) EMBRAPA = Campina Grande-PB; Fundação MT = Rondonópolis-MT; IAC = Campinas-SP; IAPAR = Londrina-PR; EPAMIG = Uberaba-MG; COODETEC = Cascavel-PR; (Private companies) DELTA PINE, Uberlândia-MG, Brazil; BAYER SEEDS, Patos de Minas-MG, Brazil; SYNGENTA, São Paulo-SP, Brazil. Cultivar 1 came from CSIRO in Australia, cultivars 19, 20 \& 21 from INTA in Argentine and cultivar 43 from Paraguay. ${ }^{2}$ Information obtained by personal communications supplemented with information obtained in the literature. ${ }^{3}$ Key to Brazilian states: $\mathrm{BA}=$ Bahia; $\mathrm{GO}=$ Goiás; $\mathrm{MG}=$ Minas Gerais; $\mathrm{MS}=$ Mato Grosso do Sul; $\mathrm{MT}=$ Mato Grosso; $\mathrm{PR}=$ Paraná; $\mathrm{SP}=\mathrm{São}$ Paulo; $\mathrm{TO}=$ Tocantins. Note: In all columns, a dash (-) indicates that data was unavailable for this item.

The quality of the DNA was evaluated by photospectrometry using the $260 / 280 \mathrm{~nm}$ absorbance ratio method and by electrophoreses in $0.8 \%(\mathrm{w} / \mathrm{v})$ agarose gel and the DNA concentration estimated at $260 \mathrm{~nm}$ (Sambrook et al., 1989). The stock DNA samples were stored at $-20^{\circ} \mathrm{C}$ and working DNA samples (containing $10 \mathrm{ng} \mu \mathrm{L}^{-1}$ ) at $4{ }^{\circ} \mathrm{C}$.

\section{Microsatellite markers and amplification conditions}

To select the markers to be used for investigating our 53 cotton cultivars we screened 12 cotton cultivars using
116 BNL (made available by Research Genetics) and 86 JESPR primer pairs (Reddy et al., 2001) synthesized by Invitrogen Life Technologies as CNL primers, of which $34 \mathrm{BNL}$ pairs and $1 \mathrm{CNL}$ pair were polymorphic. However, only 31 primer pairs produced easily-detected products (Table 2).

Amplifications were carried out in $200 \mu \mathrm{L}$ microtubes containing $15 \mu \mathrm{L}$ of reaction mix consisting of $30 \mathrm{ng}$ of template, $0.2 \mu \mathrm{M}$ of each primer, 1 unit of Taq DNA polymerase, $0.2 \mathrm{mM}$ of each dNTP, 0.2 to $0.3 \mathrm{mM}$ of 
Table 2 - Locus, PCR $\mathrm{MgCl}_{2}$ concentration and allele product size (bp), number, frequency and polymorphism information content (PIC) for the 31 microsatellite loci used in the analysis of the 53 cotton cultivars shown in Table 1.

\begin{tabular}{|c|c|c|c|c|c|}
\hline Microsatellite locus & $\mathrm{MgCl}_{2}(\mathrm{mM})$ & Product size (bp) & Number of alleles & Allele frequency & PIC \\
\hline BNL139 & 3 & $150-170$ & 3 & $0.06 ; 0.69 ; 0.25$ & 0.46 \\
\hline BNL 946 & 2.5 & $330-350$ & 2 & $0.85 ; 0.15$ & 0.26 \\
\hline BNL 1053 & 2 & $170-190$ & 2 & $0.57 ; 0.43$ & 0.49 \\
\hline BNL 1064 & 2.5 & $130-140$ & 2 & $0.11 ; 0.89$ & 0.19 \\
\hline BNL1231 & 2.5 & $170-200$ & 2 & $0.68 ; 0.32$ & 0.44 \\
\hline BNL1423 & 3 & $130-140$ & 2 & $0.58 ; 0.42$ & 0.49 \\
\hline BNL 1673 & 2.5 & $300-360$ & 2 & $0.13 ; 0.87$ & 0.23 \\
\hline BNL 1694(2) & 2.5 & $230-260$ & 2 & $0.50 ; 0.50$ & 0.50 \\
\hline BNL 1721 & 2.5 & $170-180$ & 2 & $0.24 ; 0.76$ & 0.36 \\
\hline BNL 2448 & 2.5 & $130-140$ & 2 & $0.87 ; 0.13$ & 0.23 \\
\hline BNL 2449 & 3 & $140-170$ & 3 & $0.74 ; 0.03 ; 0.24$ & 0.40 \\
\hline BNL 2495 & 2.5 & $190-200$ & 2 & $0.55 ; 0.45$ & 0.50 \\
\hline BNL 2496A & 3 & $110-120$ & 2 & $0.72 ; 0.28$ & 0.41 \\
\hline BNL 2590 & 2.5 & $180-190$ & 2 & $0.82 ; 0.18$ & 0.29 \\
\hline BNL 2646 & 3 & $120-150$ & 2 & $0.31 ; 0.69$ & 0.43 \\
\hline BNL 2921 & 2.5 & $150-160$ & 2 & $0.56 ; 0.44$ & 0.50 \\
\hline BNL 2960 & 3 & $140-150$ & 2 & $0.51 ; 0.49$ & 0.50 \\
\hline BNL 2986 & 3 & $150-160$ & 2 & $0.52 ; 0.48$ & 0.50 \\
\hline BNL 3089 & 2.5 & $140-150$ & 2 & $0.90 ; 0.10$ & 0.18 \\
\hline BNL 3171 & 2.5 & $210-230$ & 2 & $0.28 ; 0.72$ & 0.40 \\
\hline BNL 3255 & 3 & $220-240$ & 2 & $0.33 ; 0.67$ & 0.44 \\
\hline BNL 3257 & 2.5 & $200-220$ & 3 & $0.49 ; 0.32 ; 0.19$ & 0.62 \\
\hline BNL 3408(2) & 2.5 & $140-150$ & 2 & $0.50 ; 0.50$ & 0.50 \\
\hline BNL 3482 & 2.5 & $120-130$ & 2 & $0.76 ; 0.24$ & 0.37 \\
\hline BNL 3590 & 2 & $170-190$ & 3 & $0.07 ; 0.56 ; 0.37$ & 0.55 \\
\hline BNL 3594 & 2.5 & $170-190$ & 2 & $0.89 ; 0.11$ & 0.20 \\
\hline BNL 3800 & 2 & $180-190$ & 2 & $0.83 ; 0.17$ & 0.28 \\
\hline BNL 3838 & 2.5 & $120-130$ & 2 & $0.73 ; 0.27$ & 0.39 \\
\hline BNL 3902 & 2 & $170-200$ & 2 & $0.58 ; 0.42$ & 0.49 \\
\hline BNL 4030 & 2.5 & $110-120$ & 2 & $0.32 ; 0.68$ & 0.44 \\
\hline CNL 101 & 2.5 & $120-130$ & 2 & $0.37 ; 0.63$ & 0.47 \\
\hline Total & \multicolumn{5}{|c|}{66} \\
\hline Mean & & & 2.13 & & 0.40 \\
\hline
\end{tabular}

$\mathrm{MgCl}_{2}$ (Table 2) and $1 \mathrm{X}$ reaction buffer $(10 \mathrm{mM}$ Tris-HCL and $50 \mathrm{mM} \mathrm{KCl}, \mathrm{pH} 8.3)$. The amplification was carried out in a Perkin Elmer thermocycler (Gene Amp PCR System 9600) using a touch-down program consisting of a denaturation step of $4 \mathrm{~min}$ at $94{ }^{\circ} \mathrm{C}$ followed by a touch-down profile starting with 10 cycles of $40 \mathrm{~s}$ at $94^{\circ} \mathrm{C}$, a pairing step of $40 \mathrm{~s}$ at $65^{\circ} \mathrm{C}$ decreasing by $1{ }^{\circ} \mathrm{C}$ per cycle until $55^{\circ} \mathrm{C}$, and $1 \mathrm{~min}$ at $72^{\circ} \mathrm{C}$. After touch-down profiling the mixture was subjected to 30 cycles of $40 \mathrm{~s}$ at $94{ }^{\circ} \mathrm{C}, 40 \mathrm{~s}$ at $55^{\circ} \mathrm{C}$ and $1 \mathrm{~min}$ at $72{ }^{\circ} \mathrm{C}$. The program ended with one polymerization cycle at $72{ }^{\circ} \mathrm{C}$ for $7 \mathrm{~min}$.

The amplified fragments were separated electrophoretically using a denaturing gel consisting of $7 \%(\mathrm{w} / \mathrm{v})$ polyacrylamide (19:1 acrylamide:bisacrylamide), $32 \%$ (w/v) formamide and 5.6 M urea (Litt et al. 1993). A $10 \mathrm{bp}$ DNA ladder (Life Technologies, Cat number 10821-015) was spotted on each gel as a fragment length standard. The gels were stained for 30 min using ethidium bromide $\left(1 \mu \mathrm{g} \mathrm{mL}^{-1}\right)$ and photographed under ultraviolet light (Eagle Eye II). Fragment length was determined visually by comparison with the DNA ladder and by using the One-Dscan program (version 1).

\section{Data analysis}

The genetic diversity of each microsatellite locus was obtained by calculating the frequency of the microsatellite allele based on polymorphism information content (PIC) using the equation: 


$$
\mathrm{PIC}=1-j=1-\sum_{j=1}^{n} p_{i j}^{2}
$$

where $p i j$ is the frequency of the $j^{\text {th }}$ allele for primer $i$ (Anderson et al., 1993). The identity probability (IP) represents the probability that two cultivars are equal due to randomness and was calculated using the equation:

$$
\mathrm{IP}=\sum_{i=1}^{n}\left(p_{i}^{2}\right)^{2}+\sum_{i=1}^{n} \sum_{j=i+1}^{n}\left(2 p_{i} p_{j}\right)^{2}
$$

where $p_{i}$ and $p_{j}$ are the frequencies of alleles $i$ and $j$ where $i \neq j$. The combined IP was obtained by multiplying the IP value for each locus.

Genetic distances between cultivars were calculated using a dissimilarity matrix constructed using the similarity index complement (SI) for co-dominant and or multiallelic variables calculated using the Genes program (Cruz, 2001). The SI estimated the similarity between genotypes for each cultivar by awarding a score to each microsatellite (i.e. 0 when an allele was absent, 1 when the allele was heterozygous and 2 when it was homozygous), the SI being calculated by dividing the total number of common alleles by the total number of alleles evaluated. Cluster analysis was carried out using tocher analysis, single linkage and complete linkage dissimilarity matrices and the unweighted pairgroup method using arithmetic average (UPGMA) and the dendrogram resulting from these calculations plotted using the STATISTICA program (StatSoft Inc., 1999).

The efficiency of the cluster analysis was evaluated by the cophenetic correlation coefficient, taking into account the concordance between the original dissimilarity matrices and the dendrogram. The calculation of cophenetic correlation $\left(r_{c o f}\right)$ was carried out using the equation:

$$
r_{c o f}=r_{D C}=\frac{C \hat{O} V(D, C)}{\sqrt{\hat{V}(D) \hat{V}(C)}}
$$

where $D$ represents the distances matrix and $C$ the cophenetic matrix obtained from the dendrogram. The correlation significance level was evaluated using the Mantel $Z$ statistic (Mantel, 1967) and the significance of $Z$ determined using the Genes program by comparing the observed $Z$ values with a critical $Z$ value obtained by calculating $Z$ for one matrix with 5000 permuted variants of the second matrix.

\section{Results and Discussion}

\section{Microsatellite allelic diversity}

For the 53 cotton cultivars evaluated we found that 31 primer pairs amplified 33 loci, with the BNL 1964 and BNL 3408 primers amplifying two loci, one of which was polymorphic. In their cotton microsatellite marker mapping study, Liu et al. (2000a) also found that some primers (including BNL 3408) amplified two loci.
The primers amplified a total of 66 alleles to give an average of 2.13 alleles per microsatellite locus (Table 2), similar to that found in cotton by Gutiérrez et al. (2002) who used 60 pairs of polymorphic primers to which amplify 69 loci resulting in a total of 139 alleles and an average of 2 alleles per locus. However, Liu et al. (2000b) used 56 polymorphic primer pairs to amplify 62 cotton loci and produce a total of 325 alleles with average of 5 alleles per locus.

The PIC value calculated to estimate the informativeness of each primer varied from 0.18 to 0.62 with an average of 0.40 (Table 2), within the range of the PIC values calculated by Liu et al. (2000b) who found that cotton PIC values varied from 0.05 to 0.82 with an average value of 0.31. The fact that our PIC values were somewhat lower than those found by Liu et al. (2000b) might be due to the fact that the cultivates used in our study came from breeding programs and might therefore have a narrow genetic base. In contrast, Liu et al. (2000b) used 97 wild $G$. hirsutum accessions, which might explain the higher polymorphism ( 5 alleles per locus) found by these authors. However, it should also be pointed out the PIC average value found by Liu et al. (2000b) was 0.31, which means that when the PIC general mean was taken into account for all loci they actually found low polymorphism. Gutiérrez et al. (2002) found an average of 2 alleles per microsatellite locus, but a large number of the cotton cultivars used came from breeding programs in the United States and Australia which are known to have a narrow genetic base (Multani and Lyon, 1995; Iqbal et al., 1997; Ulloa et al., 1999; Gutiérrez et al., 2002).

The most informative primers were BNL primers $3257,3590,3408,2495$ and 1694. According to maps presented by Liu et al. (2000a) and Lacape et al. (2003), 13 primer sites are located in sub-genome A, two on chromosome 5, two on chromosome 6 and two on chromosome 9, the other sites being distributed on chromosomes 2, 3, 7, 8 (A02), 10, 11 (A08) and 12. The sites for the remaining 11 primers are located in sub-genome $\mathrm{D}$, two on chromosome 15 , two on chromosome 20 , two on chromosome 26 and the others are distributed on chromosomes 16, 17, 18, 21 (D02) and 22. The other seven primers were not mapped. This data shows that the great majority of primers used in our study were found to be well-distributed over the cotton genome.

A microsatellites profile was constructed for each cultivar using 31 primer pairs which were able to discriminate between 52 of the 53 cultivars studied (98\%), the two cultivars that could not be separated being Sicala 3-2 and CNPA ITA 90. The probability that these two cultivars were equal due to randomness was calculated based on the frequency product of the alleles detected in these cultivars and was found to be very small $\left(4.07 \times 10^{-13}\right.$ for each microsatellite locus). However, the genealogy of the plants clarifies the situation in that the Sicala 3-2 cultivar origi- 
nated from a cross between the Acala and Tamcot SP-37 varieties and the DP 61 and CSIRO varieties while the CNPA ITA 90 cultivar was a selection of the Deltapine Acala (DPAc90) cultivar which was produced from a cross involving DP 16 and John Cotton Polycross cultivars. Both the DP 61 and CSIRO varieties are selections from the DP 16 cultivar while the John Cotton Polycross cultivars originated from a complex cross involving the Acala and Tamcot SP-37 varieties.

Based on the PIC values of the most informative loci it is possible to greatly reduce the number of loci employed in cultivar discrimination. Employing only the primers BNL 3257, 3590, 2495, 2921, 1694, 3408, 2960, 1053, 1423,139 and 3255 instead of 31 primers it is possible to differentiate 52 cultivars. The 11 BNL cited above can be used to generate genetic profile definitions (genetic fingerprints) for each cultivar which should be of help in cultivar protection research, genetic purity analysis and other studies designed to be of assistance to breeding programs, such as monitoring crossing, pollen contamination rates, accuracy during controlled crossing, etc.

\section{Genetic distance and diversity}

The coefficient of dissimilarity used to calculate the genetic distance between the 53 cultivars evaluated using microsatellite loci varied from 0.00 to 0.71 with average of $0.40 \pm 0.01$. The distribution analysis of 1.378 pairs of the compared cultivars (Figure 1) displayed a concentration of values in the classes from 0.3-0.4 to 0.4-0.5, with a value of zero indicating similarity and values between 0.7 and 0.8 divergence. The highest genetic distance $(0.71)$ occurred between cultivars IAC 20 and BRS Itaúba and the lowest distance (0.00) between Sicala 3-2 and CNPA ITA 90.

Figure 1 shows a high similarity between the cultivars as did cluster analysis. The cophenetic correlations between dissimilarity data and the phenetic matrixes for the 53 cultivars were $65 \%$ for the UPGMA method, $63 \%$ for

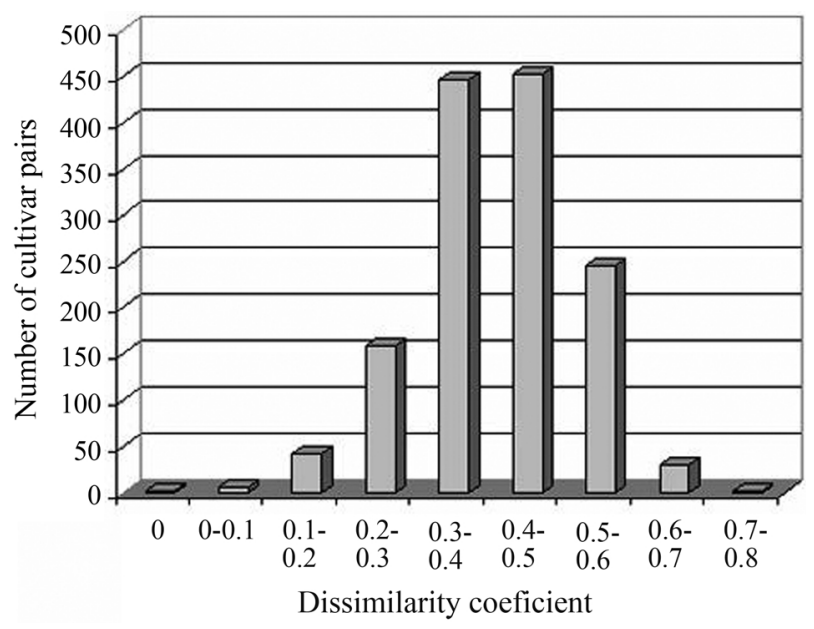

Figure 1 - Distribution of genetic distance calculated for 1.378 cultivar pairs. the single linkage method and $43 \%$ for the complete linkage method, these values being significant $(\mathrm{p}=0.01)$ based on 5000 simulations. The complete linkage method showed the closest agreement with the results obtained by the UPGMA method and UPGMA clustering, complete linkage and Tocher analysis (not shown) were highly correlated. The UPGMA method (Figure 2) was the most efficient at representing the dissimilarity between the evaluated genotypes, this method being known to be the hierarchical method producing dendrograms with maximum cophenetic correlation (Cruz and Carneiro, 2003).

Multani and Lyon (1995), using RAPD markers, also been found low genetic distance values $(0.01$ to 0.08$)$ between nine Australian cotton cultivars and Iqbal et al. (1997) found low genetic distances ( 0.18 to 0.07 ) between 17 G. hirsutum cultivars, also using RAPD markers. Ulloa et al. (1999) used microsatellite markers to investigate genetic distance in cotton and found that the distance between the Acala and Delta cultivars was 0.18 while that among the Pima PS series of cultivars was 0.16 and work by Gutiérrez et al. (2000) using microsatellite markers has detected narrow genetic distance between Australian and American Cultivars. Van Esbroeck et al. (1998) have pointed out that the monoculture of some successful cultivars and their extensive use as progenitors in breeding programs has limited the genetic diversity of cultivated cotton cultivars.

The threshold value for grouping samples in a dendrogram is generally empirical, but the best threshold for grouping is generally considered to be the point where there is a large distance between groups or where there is a clear nesting of taxonomic units. In our study, the dendrogram of the relationship between the 53 cultivars showed two large groups (group A at a genetic distance threshold of 50\% and group B at a threshold of 35\%) and seven well-nested subgroups (Figure 2).

The majority of group A cultivars were obtained by selection and are planted in the semi-arid Brazilian cerrado and have a long cropping-cycle of 140 to 180 days and about $40 \%$ final fiber percentage. The group B cultivars were produced by crossing and are recommended for planting in almost all regions of Brazil but are mainly planted in central-western and southeastern regions, the majority of group B cultivars being virus resistant and have a short cropping-cycle of about 110 to 140 days and about 38 final fiber percentage.

The seven subgroups exhibited independence between genetic clustering and cultivar characteristics such as origin, planting region and cropping-cycle. It was interesting to note that in each of the seven groups there were cultivars from several origins (Research institutes, private breeding companies), indicating that the organizations producing cultivars employ similar germplasm which is shared between them. The formation of subgroups (Figure 2) is consistent with the genealogical information obtained for some of the cultivars. Subgroup 1, for example, contains 


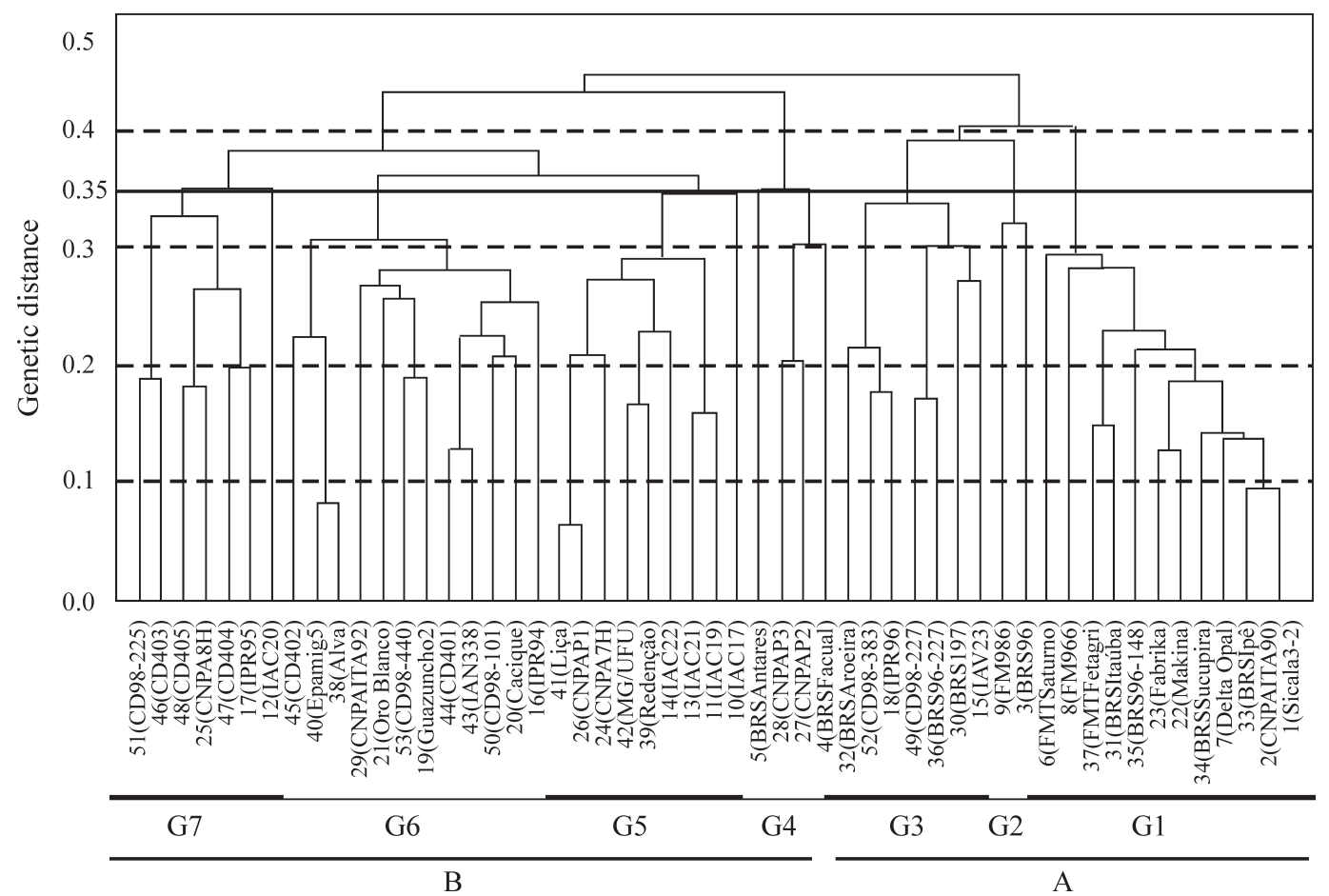

Figure 2 - UPGMA dendrogram constructed based on dissimilarities measures of 53 cotton cultivars. Groups A and B were obtained considering an upper dissimilarity limit of $50 \%$ while the G1, G2, G3, G4, G5, G6 and G7 subgroups shown below the figure were obtained considering an upper-limit of $35 \%$.

some cultivars which have CS-50, Sicala 34 and CNPA SRI5 as parents but both CS 50 and Sicala 34 cultivars have Deltapine Acala 90 and Siokra 1-1 as parents, with Siokra 1-1 in its turn having the same parents as Sicala 3-2 (Table 1). Subgroup 3 contains some cultivars which have Deltapine Acala 90 and IAC 20 as parents (Table 1), the fact that cultivar IAPAR 71 is a selection from IAC 20 may explain the presence of cultivar IPR 96 within this subgroup. Subgroup 4 contains cultivars CNPA P2 and CNPA P3 which both have the same genealogy, thus explaining the presence of these cultivars within the same group. Subgroup 5 is made up of cultivars with parents including IAC RM3, Tamcot SP-37 and IAC 17 (Table 1). Subgroup 6 contains the cultivars CD 401, Cacique, Guazuncho, Oro Blanco and IAN 338 which have parents whose genealogy shows cultivars such as Chaco 510, Guazuncho, Reba P279 and SP 8535 (Table 1). It is interesting to note that cultivar CNPA SRI5 was obtained from a population with a large base, with several cultivars being involved in its genealogy, which may explain the presence of cultivars obtained from CNPA SRI5 in various subgroups.

Although some subgroups were formed which were consistent with the genealogy of the cultivars some inconsistencies were also evident. For example, cultivars IPR 95 and IPR 96 have the same parents but they were clustered in different subgroups even though they shared $72 \%$ similarity and this also occurred with other cultivars, (e.g. BRS Facual and BRS Sucupira) which were 58\% similar. The fact that cultivar CNPA SRI5 was produced as a rest of a complex cross may explain the divergence between these cultivars. Cultivars such as Epamig 5 and Alva have the same origin, presented $92 \%$ similarity and were clustered in the same group. The presence of cultivars BRS 96 and Fiber Max 986 in the same group is also inconsistent with the genealogy of these cultivars.

The lack of information about some genealogies may be a factor that led to the inconsistencies mentioned above. According to Carvalho et al. (2003) the lack of genealogy makes it difficult to estimate diversity using genealogical studies and Van Esbroeck et al. (1999) found no relationship between cotton genealogy and similarity measurements based on morphological and agronomic features. Tatineni et al. (1996) detected a 0.63 correlation between the genetic similarity of cotton lines calculated using RAPD markers and morphological features. In general, however, there is little information with respect to the correlation between cotton genetic distances based on molecular markers and genealogical studies.

In our study we observed that a large number of the cultivars studied descended from a few original cultivars (e.g. Auburn 56, Tamcot SP-37, DP Smoothleaf and DP 45) thus narrowing their genetic base and possibly making them vulnerable to the present and future diseases. In a similar way to Brazilian cultivars, cultivated upland $G$. hirsutum presents limited genetic diversity (Wendel et al. 1992; Wendel and Brubaker 1993; Tatineni et al. 1996; Iqbal et al. 1997). According to Iqbal et al. (2001), one hypothesis which may explain the apparent lack of diversity 
in cultivated upland G. hirsutum is that one or more genetic bottlenecks may have occurred during the later stages of the development of G. hirsutum latifolium, possibly as a result of rigorous selection for early maturity. Much of the original genetic diversity of G. hirsutum, including valuable alleles that confer resistance to insects, pathogens and environmental adversities, would have been lost during this phase of its domestication. Iqbal et al. (2001) also pointed out that the G. hirsutum cultivated around the world is derived from upland cottons from the USA which were exported to other countries in the 19th and early twentieth century, with most upland cotton used in early Brazilian cotton breeding coming from this source. They also observed that Pakistan cotton breeding coming from this source.

It is interesting to note that in our study we found that the majority of cultivars obtained from the different breeding programs resulted from selection programs involving previously successful cultivars or, less often, crosses between cultivars or between cultivars and lines. Van Esbroeck and Bowman (1998) have suggested some explanations to justify crosses between closely related individuals in cultivar breeding programs. These authors have argued that there is enough allelic variation, mutation or recombination in crosses between closely related individuals to allow improvement in agronomic performance and/or that the coefficient of parentage may not reflect the real genetic distance. The great number of successful cultivars obtained through reselection show that a small quantity of recombination results in sufficient genetic variance to produce genetic progress within breeding programs. Even so, great efforts are currently being made to reduce the genetic vulnerability of cultivars by introducing more diversified germplasm into cotton cultivars while avoiding negative effects on those cultivars already adapted to particular countries or regions, and will bring many rewards to the culture breeding.

\section{Acknowledgments}

The authors are most grateful to the Cooperativa Central de Pesquisa Agrícola (COODETEC), EMPRAPA, EPAMIG, IAC and IAPAR for their support in supplying the cotton seeds analyzed in the current study. This research received financial support from the Brazilian agency Conselho Nacional de Pesquisa e Desenvolvimento (CNPq)

\section{References}

Abdalla AM, Reddy OUK, El-Zik KM and Pepper AE (2001) Genetic diversity and relationships of diploid and tetraploid cottons revealed using AFLP. Theoretical and Applied Genetic 102:222-229.

Anderson JA, Churchill GA, Autrique JE, Tanksley SD and Sorrells ME (1993) Optimizing parental selection for genetic linkage maps. Genome 36:181-186.
Brubaker CL and Wendel JF (1994) Reevaluating the origin of domesticated cotton (Gossypium hirsutum, Malvaceae) using nuclear restriction fragment length polymorphism (RFLPs). American Journal of Botany 81:1309-1326.

Carvalho LP, Lanza MA, Fallieri J and Santos JW (2003) Análise da diversidade genética entre acessos de banco ativo de germoplasma de algodão. Pesquisa Agropecuária Brasileira 38:1149-1155.

Cruz CD (2001) Programa Genes, Versão Windows: Aplicativo Computacional em Genética e Estatística. UFV, Viçosa, 648 pp.

Cruz CD and Carneiro PCS (2003) Modelos biométricos aplicados ao melhoramento genético. v. 2. UFV, Viçosa, 585 pp.

Gutiérrez OA, Basu S, Saha S, Jenkins JN, Shoemaker DB, Cheatham CLA and McCarty Jr JC (2002) Genetic distances among selected cotton genotypes and its relationship with $\mathrm{F}_{2}$ performance. Crop Science 42:1841-1847.

Iqbal MJ, Aziz N, Saeed NA and Zafar Y (1997) Genetic diversity evaluation of some elite cotton varieties by RAPD analysis. Theoretical and Applied Genetic 94:139-144.

Iqbal MJ, Reddy OUK, El-Zik KM and Pepper AE (2001) A genetic bottleneck in the 'evolution under domestication' of upland cotton Gossypium hirsutum L. examined using DNA fingerprinting. Theoretical and Applied Genetics 103:547554.

Lacape JM, Nguyen TB, Thibivilliers S, Courtois B, Bojinov BM, Cantrell RG, Burr B and Hau B (2003) A combined RFLPSSR-AFLP map of tetraploide cotton based on a Gossypium hirsutum x Gossypium barbadense backcross population. Genome 46:612-626.

Litt M, Hauge X and Sharma V (1993) Shadows bands seen when typing polymorphic dinucleotide repeats: Some causes and cures. Biotechniques 15:280-284.

Liu S, Saha S, Stelly D, Burr B and Cantrell RG (2000a) Chromosomal assignment of microsatellite loci in cotton. Journal of Heredity 91:326-332.

Liu S, Cantrell RG, McCarty-Jr JC, Stewart J McD (2000b) Simple sequence repeat based assessment of genetic diversity in cotton race stock Accessions. Crop Science 40:1459-1469.

Lu HJ and Myers GO (2002) Genetic relationships and discrimination of ten influential upland cotton varieties using RAPD markers. Theoretical and Applied Genetic 105:325-331.

Mantel NA (1967) The detection of disease clustering and a generalized regression approach. Cancer Research 27:209-220.

McDonald MB, Elliot LJ and Sweeney PM (1994) DNA extraction from dry seeds for RAPD analyses in varietal identification studies. Seed Science \& Technology 22:171-176.

Multani DS and Lyon BR (1995) Genetic fingerprinting of Australian cotton cultivars with RAPD markers. Genome 38:1005-1008.

Nguyen TB, Giband M, Brottier P, Risterucci AM and Lacape JM (2004) Wide coverage of the tetraploide cotton genome using newly developed microsatellite markers. Theoretical and Applied Genetic 109:167-175.

One-Dimensional Gel Analyze. ONE-Dscan, ver. 1.0, Copyright 1994/1995, Scanaliytic, a dimensional CST Inc.

Pillay M and Myers GO (1999) Genetic diversity assessed by variation in ribosomal RNA genes and AFLP markers. Crop Science 39:1881-1886. 
Powell W, Machray GC and Provan J (1996) Polymorphism revealed by simple sequence repeats. Trends in Plant Sciences $1: 215-222$.

Reddy OU, Pepper AE, Abdurakhmonov I, Saha S, Jenkins JN, Brooks T, Bolek Y and El-zik KM (2001) New dinucleotide and trinucleotide microsatellite marker resources for cotton genome research. Crop Science 5:103-113.

Sambrook J, Fritsch EF and Maniatis T (1989) Molecular Cloning: Laboratory Manual, 2nd edition, v. 3. CSHL, Cold Spring Harbor, NY, appendix C-1.

Schuster I, Queiroz VT, Teixeira AI, Barros EG and Moreira MA (2004) Determinação da pureza varietal de sementes de soja com o auxílio de marcadores microssatélites. Pesquisa Agropecuária Brasileira 39:247-253.

StaSoft Inc (1999) STATISTICA for Windows [Computer program manual]. Tulsa. http://www.statsoft.com.

Tatineni V, Cantrell RG and Davis DD (1996) Genetic diversity in elite cotton germplasm determined by morphological characteristics and RAPDs. Crop Science 36:186-192.
Ulloa M, Meredith-Jr WR, Percy R and Moser H (1999) Genetic variability within improved germplasm of Gossypium hirsutum and G. barbadense cottons. Agronomy abstracts, ASA, Madison, pp 73.

Van Esbroeck GA and Bowman DT (1998) Cotton germplasm diversity and its importance to cultivar development. Journal of Cotton Science 2:121-129.

Van Esbroeck GA, Bowman DT, Calhoun DS and May OL (1998) Changes in the genetic diversity of cotton in the USA from 1970 to 1995. Crop Science 38:33-37.

Van Esbroeck GA, Bowman DT, May OL and Calhoun DS (1999) Genetic similarity indices for ancestral cotton cultivars and their impact on genetic diversity estimates of modern cultivars. Crop Science 39:323-328.

Wendel JF and Brubaker CL (1993) RFLP diversity in Gossypium hirsutum L. and new insights into the domestication of cotton. American Journal of Botany 80:71.

Wendel JF, Brubaker CL and Percival AE (1992) Genetic diversity in Gossypium hirsutum and the origin of upland cotton. American Journal of Botany 79:1291-1310.

Associate Editor: Márcio de Castro Souza Filho 